\title{
EGU21-9552
}

https://doi.org/10.5194/egusphere-egu21-9552

EGU General Assembly 2021

(c) Author(s) 2022. This work is distributed under

the Creative Commons Attribution 4.0 License.

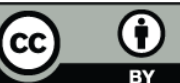

\section{Satellite- and station-based climatology of low-level cloud cover during the long dry season in western Central Africa}

\author{
Raffael Aellig ${ }^{1}$, Judith Gerighausen ${ }^{1}$, Andreas Fink ${ }^{1}$, Peter Knippertz ${ }^{1}$, and Nathalie Philippon ${ }^{2}$ \\ ${ }^{1}$ Karlsruher Institute of Technology, Institute for Meteorology and Climate Research, Troposphere Research, Karlsruhe, \\ Germany (raffael.aellig@kit.edu) \\ ${ }^{2}$ Institut des Géosciences de l'Environnement Grenoble
}

Low-level cloud cover (LCC) in western Central Africa is an important factor for the persistence of the dense evergreen tropical forest, as it keeps conditions cool, humid, and light-deficient. A quantitative understanding of the mechanisms controlling LCC is an important prerequisite to anticipate future changes, particularly as climate and weather models have been shown to struggle with a realistic representation of low clouds. This is a major goal of the French-German project Dynamics, Variability, and Bioclimatic Effects of Low Clouds in Western Central Africa (DYVALOCCA, ) launched in 2020.

Here we present an analysis of historical station data from the database ISD (Integrated Surface Database) and MIDAS (Met Office Data Archive System), ERA-5 reanalysis, and satellite data from the Meteosat Second Generation (MSG) focusing on the country of Gabon and surroundings. Station data (ISD and MIDAS) show a higher LCC during the major dry season months of July, August, and September (JAS) compared to the two rainy seasons and the other shorter dry season in boreal winter. During typical days in JAS, the LCC that thickens at night tends to break up at daytime near the coast and over the interior plateau, while it remains overcast at the windward site and over the crests of the Crystal and Chaillu low mountain ranges. Thus, stations at the coast have a different diurnal LCC cycles compared to stations in the interior of Gabon. The diurnal amplitudes of LCCs in the interior are lower and the maximum and minimum LCC occurs later in the day compared to coastal stations.

A comparison to the station data shows that LCC is generally underestimated in ERA-5. At the diurnal scale, LCC over the plateaus of eastern Gabon often does not dissolve as fast as in the ERA-5 reanalysis. Data from the Spinning Enhanced Visible and Infrared Imager (SEVIRI) satellite corroborates the underestimation by ERA-5. The RGB Night Microphysical Scheme (NMS) with SEVIRI data to determine LCC in the region shows an acceptable fit to the station data. Other satellite products such as CLAAS-2 do not deliver as good an estimate of the LCC in western Central Africa as the NMS.

Future work will employ Cloudsat-Calipso data to enhance our understanding of the vertical distribution of clouds. The best suited data sets will then be used as validation data set for convection-permitting modeling studies of example nights and days. 
